\begin{tabular}{|c|c|}
\hline Title & EVALUATION OF STRUCTURAL PERFORMANCE OF PRECA ST MODULAR PIER CAP \\
\hline Author(s) & KIM, D. W.; SHIM, C.S. \\
\hline Citation & $\begin{array}{l}\text { Proceedings of the Thirteenth East A sia Pacific Conference on Structural Engineering and Construction (EA SEC-13), } \\
\text { September 11-13, 2013, Sapporo, Japan, G-6-3., G-6-3 }\end{array}$ \\
\hline Issue Date & 2013-09-13 \\
\hline Doc URL & http:/hdl.handle.net/2115/54437 \\
\hline Type & proceedings \\
\hline Note & $\begin{array}{l}\text { The Thirteenth East A sia Pacific Conference on Structural Engineering and Construction (EA SEC-13), September 11- } \\
\text { 13, 2013, Sapporo, Japan. }\end{array}$ \\
\hline File Information & easec13-G-6-3.pdf \\
\hline
\end{tabular}

Instructions for use 


\title{
EVALUATION OF STRUCTURAL PERFORMANCE OF PRECAST MODULAR PIER CAP
}

\author{
D.W. Kim ${ }^{1 *}$, C.S. Shim ${ }^{2 \dagger}$ \\ ${ }^{1}$ Department of Civil Engineering, Ph.D. Candidate Chung-Ang University, Korea \\ ${ }^{2}$ Department of Civil Engineering, Professor Chung-Ang University, Korea
}

\begin{abstract}
Recently, modular technologies are making bridge construction safer and less disruptive to the environment and traveling public. For the design of modular substructures, connection details are the most important design issues. In this paper, a modular pier cap for concrete filled steel tube (CFT) bridge piers was suggested to improve productivity of design and construction of bridge substructures. The module consists of a composite table with an embedded steel member to mitigate stress concentration of the connection. Precast segments on the table can accommodate various conditions of bridge width. Test specimens were fabricated and structural performance was evaluated. According to failure modes of the pier cap, sectional strength, vertical and horizontal shear strength, and crack control by transverse prestressing were investigated from the test results. Structural performance of the proposed modular system was evaluated by two loading conditions. Standardized modular substructures can be effectively utilized for the fast replacement or new construction of bridges.
\end{abstract}

Keywords: Modular, Pier-cap, Concrete Filled Tube, Embedded Steel.

\section{INTRODUCTION}

Modular construction is a sustainable technology because it optimizes material usage resulting in less material waste in construction industry. Prefabrication moves concrete forming, pouring, and curing operations out of the work zone, making bridge construction safer and more environmentally friendly (Shim et al. 2008, 2011). It also removes precast member construction from the critical path, thus accelerating the construction process (Restrepo et al. 2010). Flexibility and recycling of modules reduces the demand of raw materials and minimizes the amount of energy expended to create a structure. Precast bent cap was developed and applied to actual construction projects for accelerated bridge construction (Brenes 2005).

Modular bridge construction enabling better productivity of design and construction by standardized members and fast construction becomes an important issue in construction industry

\footnotetext{
* Corresponding author: Email: csshim@cau.ac.kr

† Presenter: Email: clearup7@cau.ac.kr
} 
(Shim et al. 2012(a); Shim et al. 2012(b)). Certain range of main design parameters needs to be covered by the standardized members. Even though quality of prefabricated members can be enhanced, quality control and constructability of connections of modular structures is crucial for the successful application.

In this paper, modular pier cap for CFT bridge piers was proposed to realize fast construction of bridge substructures as shown in Figure 1. For the design of modular pier cap, design issues are discussed and their verification was conducted through static tests on precast pier cap specimens.

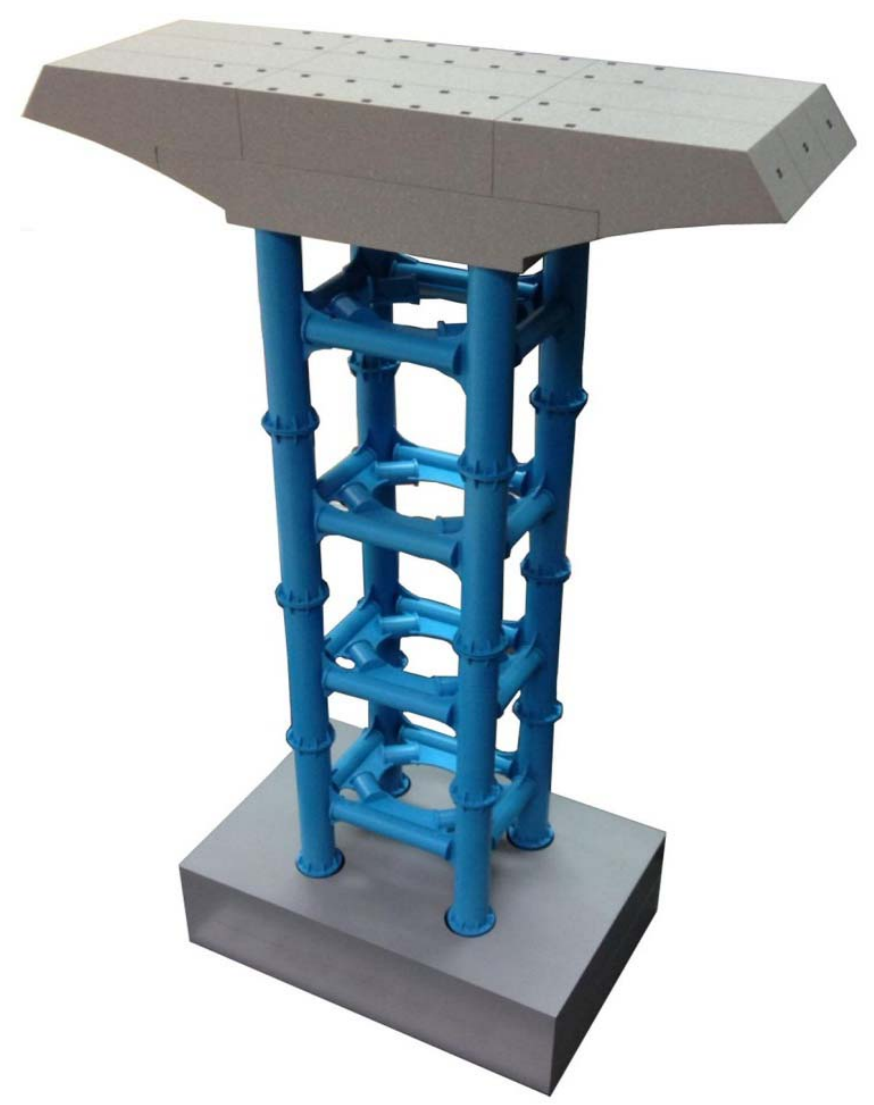

Figure 1: Modular bridge pier using CFT columns and precast pier cap

\section{DESIGN ISSUES OF PRECAST PIER CAP}

One of the design issues for the modular piers was the stress concentration due to the shallow steel tube sections. Deadweight of bridge superstructures need to be transmitted from pier cap to columns. In order to solve this problem, a steel embedded composite pier table was proposed. The steel columns were connected to the embedded steel member by bolt connection. The pier table is then connected to precast pier cap segments by vertical reinforcements. After assembly, the pier cap segments are connected by transverse prestressing. Epoxy bonding is provided for all connected surfaces. 
Design issues for the new structure are anchorage length of vertical reinforcing bars, prestressing force to control cracking, strength check of the hybrid members and bolt/weld connection between CFT columns and the pier table. Required prestressing force is determined by considering tensile stress control at the joint for service loadings and tie force at ultimate limit state as described in Figure 2. For a normal $70 \mathrm{~m}$ span continuous steel box girder bridge with $12.4 \mathrm{~m}$ width, the tie force is increased by $4.4 \%$. Four seven-wire strands are additional required for the tie force.

The modular CFT bridge pier is designed for multi-girder bridges with span length of 40m $\sim 60 \mathrm{~m}$. Considering this design condition, strength check and connection design need to be performed. According to the positions of bridge bearings, the amount of prestressing tendons, vertical reinforcing bars and dimensions of precast segments are determined.
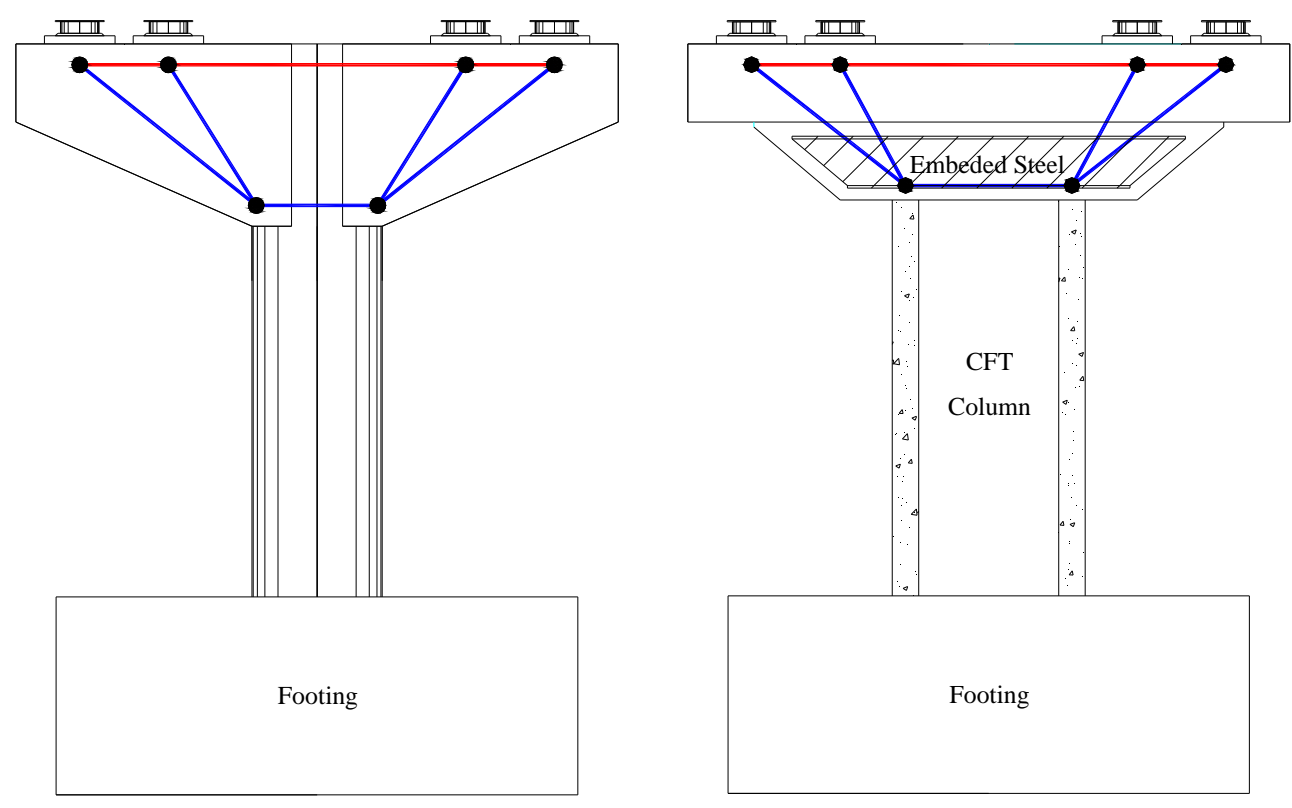

Figure 2: Design concept of a pier cap

\section{EXPERIMENTAL PROGRAM}

Two specimens were designed to investigate the flexural and shear behaviour considering different loading conditions. Modular pier caps consist of a composite pier table with embedded steel beam and three precast segments on the table, as presented in Figure 3. In order to simulate the modular CFT substructures, two CFT columns were connected to the embedded steel beam by bolt connection as presented in Figure 4. The pier table has extruded vertical reinforcing bars to obtain enough shear strength of the pier cap. Three precast segments had vertical holes to accommodate the vertical reinforcing bars. A seven wire strand was used and joints were gluded by an epoxy before the prestressing.

Average compressive strength of concrete and epoxy was $56 \mathrm{MPa}$. The grouting mortar for the holes had $43 \mathrm{MPa}$ at 14 days. The tendons had tensile strength of $1860 \mathrm{MPa}$. 

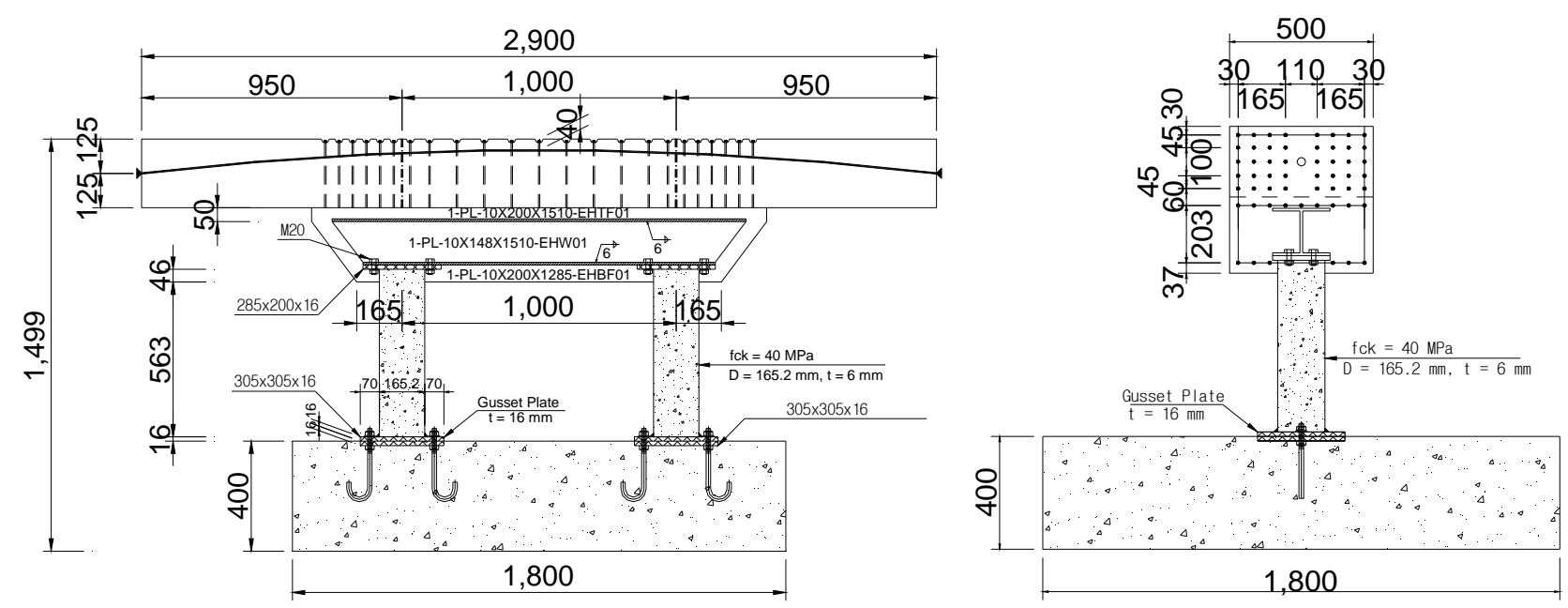

Figure 3: Test specimen.

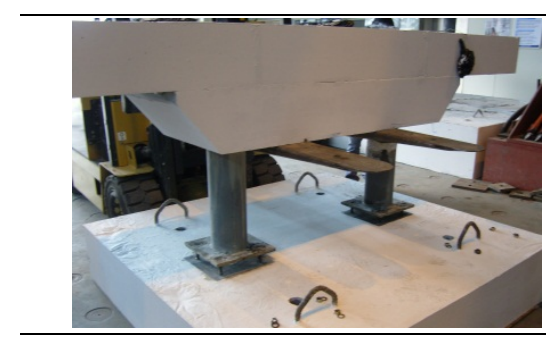

(a) Connection

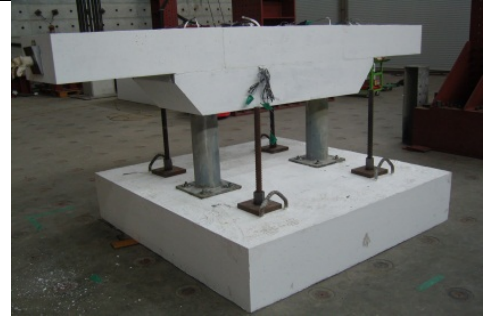

(b) Test specimen

Figure 4: Assembly of modular segments.

Two loading conditions were considered in this test. One-point central loading was conducted to observe the behaviour of the pier cap section under positive bending moment. Two-point loading was applied to the specimens after the central loading to simulate the cracking behaviour of the joints between the segments. During the tests, vertical and lateral displacements were recorded. Strains of several elements were also measured to investigate local behaviour of the pier caps.
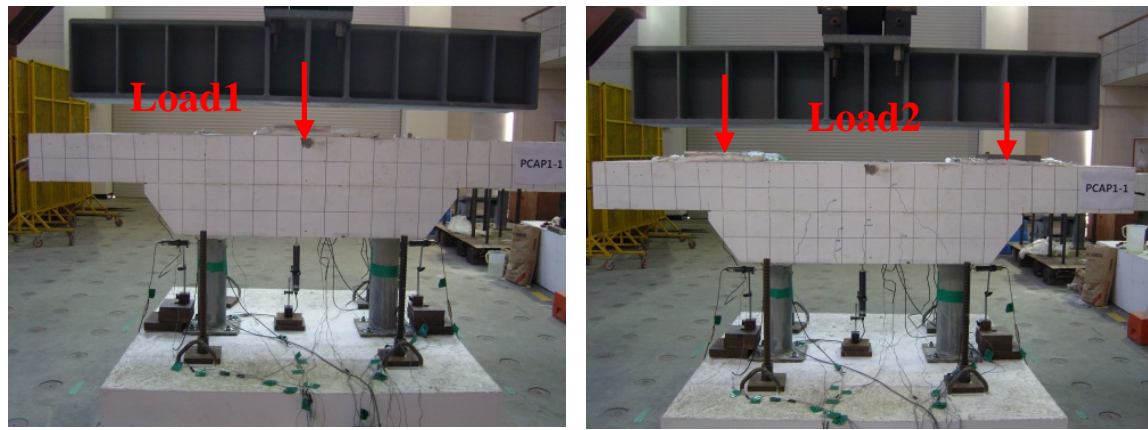

Figure 5: Loading conditions 
For the loading condition of Load 1, cracks was initiated from the bottom surface of the pier table and propagated to the precast segment section. Bottom transverse reinforcements provided well control of crack width. Diagonal cracks from the support of the CFT section to the loading position were also observed. Interface slip was not observed up to the loading of $1500 \mathrm{kN}$.

For the loading condition of Load 2, the transverse prestressing resists tensile stress of the joint to control cracking. Calculated cracking load of the pier caps are $347 \mathrm{kN}$ and $360 \mathrm{kN}$, respectively. Prestressing losses by constraint of composite section were assumed to be $15 \%$. Table 1 summarizes cracking loads for two specimens. From the measured strain of concrete and tensile reinforcements, cracking loads for PCAP1-1 and PCAP2-1 were estimated as $348.0 \mathrm{kN}$ and $520.0 \mathrm{kN}$, respectively. The joints were glued by epoxy before the prestressing. However, the cracking was initiated from the top of the joints for the two-point exterior loading condition of Load2. Then, the cracks were propagated to the composite section as the load increased. Negative bending moment of actual bridge pier caps by the loading from superstructures is normally not so considerable. Therefore, the magnitude of the transverse prestressing force needs to be decided by the full prestressing concept considering tensile stresses at the top of the joints by service loads.

Table 1: Test Specimens.

\begin{tabular}{c|c|c|c}
\hline Specimens & Test Variables & Cracking Load(Experiment) & Cracking Load(Calculation) \\
\hline PCAP1-1 & Transverse Pressing 100kN & $348 \mathrm{kN}$ & $347 \mathrm{kN}$ \\
\hline PCAP1-2 & Transverse Pressing $120 \mathrm{kN}$ & $520 \mathrm{kN}$ & $360 \mathrm{kN}$ \\
\hline
\end{tabular}

\section{CONCLUSIONS}

Experiments on modular pier caps revealed that the hybrid section can provide enough flexural strength and integral behaviour not only for positive bending moment but also for negative bending moment. Design of transverse prestressing was confirmed by observation of cracking loads.

The pier table with an embedded steel member transmitted the load from shallow steel tubes to precast segments without severe stress concentration. Bolt connection was also properly designed without premature failure by the applied loading conditions.

Further investigation on multiple modular pier cap needs to be performed by experimental programs. Simulation of axial force by deadweight of superstructures and lateral loads by wind and earthquakes needs to be done to derive design recommendations for each design issue. 


\section{ACKNOWLEDGMENTS}

This research was supported by a grant from the Construction Technology Innovation Program (10CTIPB01-Modular Bridge Research \& Business Development Consortium) funded by the Ministry of Land, Infrastructure and Transport (MLIT) of the Korean Government.

\section{REFERENCES}

Brenes F.J.(2005), Anchorage of Grouted Vertical Duct Connections for Precast Bent Caps, Ph.D. thesis, The University of Texas at Austin.

Restrepo J.I., Tobolski M.J., Matsumoto E.E.(2010). Development of a Precast Bent Cap System for Seismic Regions. National Cooperative Highway Research Program, Report 681, pp. 94-101.

Shim CS, Chung CH, Kim IK, Kim YJ.(2012 a). Rapid Emergency Replacement of Fire-damaged Composite Bridges using Precast Decks, Proceedings of International Association of Bridge Maintenance, Safety and Management (IABMAS 2012). pp. 1367-1372.

Shim CS, Chung CS, Kim HH (2008). Experimental evaluation of seismic performance of precast segmental bridge piers with a circular solid section, Engineering Structures, 30 (12), pp. 3782-3792.

Shim CS, Chung YS and Yoon JY (2011). Cyclic Behavior of Prefabricated Circular Composite Columns with Low Steel Ratio, Engineering Structures, 33, pp.2525-2534.

Shim CS, Kim DW, KONG D.(2012 b). Structural Performance of Precast Segmental Composite Pier Cap, Proceedings of $18^{\text {th }}$ International Association for Bridge and Structural Engineering (IABSE2012), Seoul, Korea, pp.611-612. 